Provided for non-commercial research and education use. Not for reproduction, distribution or commercial use.

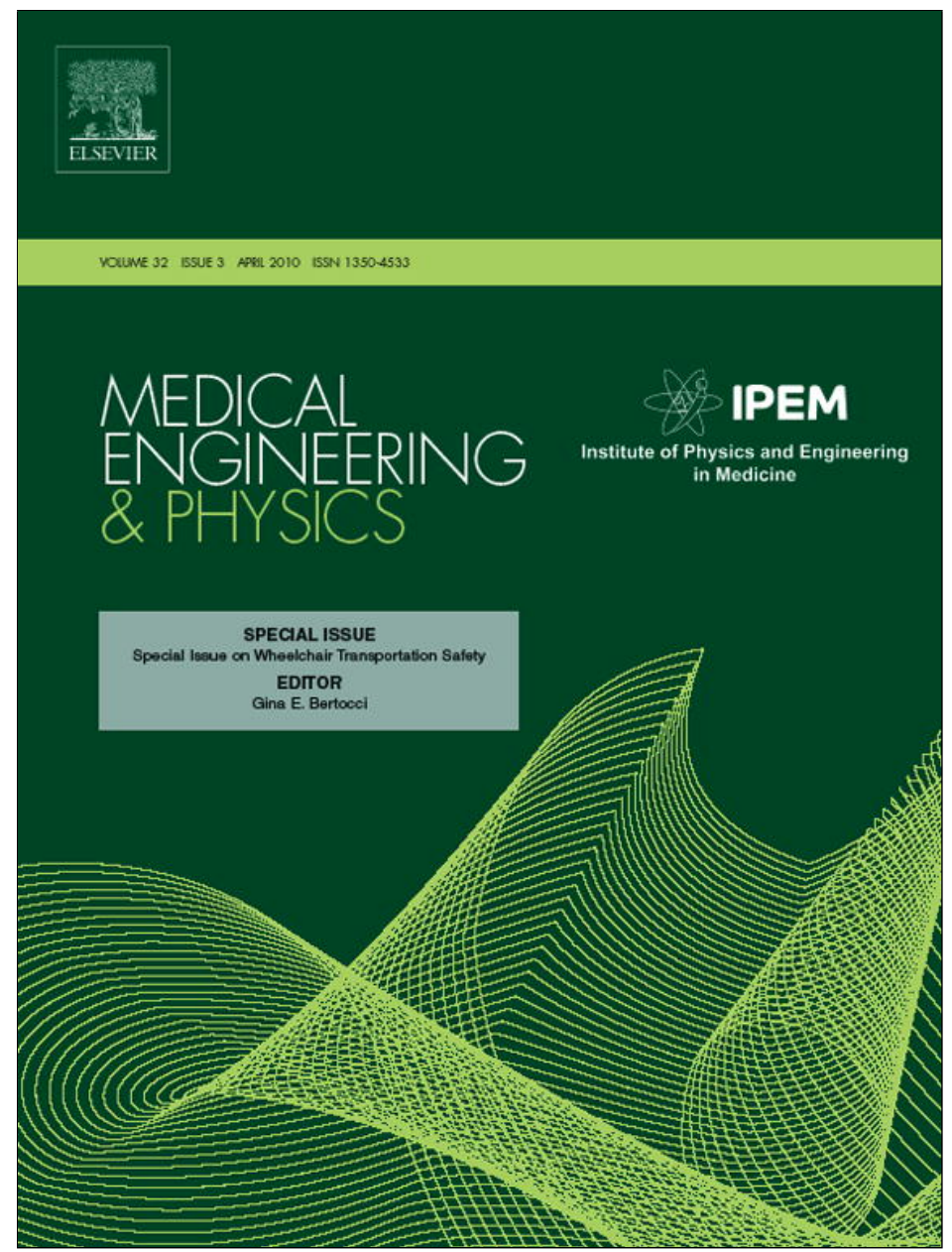

This article appeared in a journal published by Elsevier. The attached copy is furnished to the author for internal non-commercial research and education use, including for instruction at the authors institution and sharing with colleagues.

Other uses, including reproduction and distribution, or selling or licensing copies, or posting to personal, institutional or third party websites are prohibited.

In most cases authors are permitted to post their version of the article (e.g. in Word or Tex form) to their personal website or institutional repository. Authors requiring further information regarding Elsevier's archiving and manuscript policies are encouraged to visit:

http://www.elsevier.com/copyright 


\title{
Injuries in special transport services-Situations and risk levels involving wheelchair users
}

\author{
Anders Wretstrand ${ }^{\mathrm{a}, *}$, Per-Olof Bylund ${ }^{\mathrm{b}}$, Jan Petzäll ${ }^{\mathrm{c}}$, Torbjörn Falkmer $^{\mathrm{d}}$ \\ a Department of Technology and Society, Lund University, P.O. Box 118, SE-221 00 Lund, Sweden \\ ${ }^{\mathrm{b}}$ Emergency and Disaster Medical Center, University Hospital, Umeå, Sweden \\ ' Swedish Transport Agency, Norrköping, Sweden \\ d Curtin University of Technology, Perth, Australia; Jönköping University, Sweden; Linköping University, Sweden
}

\section{A R T I C L E I N F O}

\section{Article history:}

Received 15 July 2008

Received in revised form 29 June 2009

Accepted 31 July 2009

\section{Keywords:}

Wheelchair

Special transportation services

Injury incidence

Cost estimations

Travel chain perspective

STS special vehicles

STS taxis

\begin{abstract}
A B S T R A C T
Previous research has shown that wheelchair-seated passengers using special transportation services (STS) have been injured without being involved in a vehicle crash. In order to estimate incident rate and societal costs for these vehicle-related injuries, the focus needs to be adjusted towards a traveler/incidentoriented perspective. The aim of the project was to utilize such a perspective, related to travelers using STS in Sweden.

In order to address the chosen perspective, a mixed method approach was used, involving quantitative as well as qualitative research techniques applied on four different sets of data: one hospital-based record, two sets of STS incident report databases, and interviews with wheelchair-seated STS passengers.

The results showed that the injury incidence rate in STS is considerable, i.e. 10 per 100,000 trips. However, this high incidence rate is not due to road traffic collisions, but to non-collision injury incidents involving many elderly and frail passengers, who easily sustain traumas ranging from minor to moderate. The costs were estimated to be 23 million USD per annum or 14 USD per trip. Results suggest that future injury prevention measures should focus on safety in boarding and alighting procedures, as well as the continuing development of WTORS.
\end{abstract}

(C) 2009 IPEM. Published by Elsevier Ltd. All rights reserved.

\section{Introduction}

\subsection{Special transportation services}

Approximately $5 \%$ of the nine million Swedish inhabitants are permitted to use special transportation services (STS). Among them, $15 \%$ are wheelchair users who remain seated in their wheelchairs during transportation. The total annual number of wheelchair trips amounts to 1.7 millions [1]. The dominant STS solution is the door-to-door, demand-responsive taxi trip [2]. Most trips involving wheelchair users are made with STS special vehicles, e.g. converted minivans or vans. The special vehicles can carry both wheelchair-seated travelers and travelers in ordinary seats. The vehicles typically have one entrance equipped with a lifting device or ramp, normally at the rear end, and one entrance with steps at the right side of the vehicle. The most common wheelchair tie-down and occupant restraint systems (WTORS) have four straps to secure the wheelchair and a three-point seat belt for the occupant. According to the European M classification of vehicles [3],

\footnotetext{
* Corresponding author. Tel.: +46 46 2229125; fax: +46 46123272 .

E-mail address: anders.wretstrand@tft.lth.se (A. Wretstrand).
}

the special vehicles are $M_{1}, M_{2}$ or $M_{3}$ vehicles, where $M_{1}$ means vehicles comprising no more than eight seats in addition to the driver's seat, while $\mathrm{M}_{2}$ (maximum mass $<5000 \mathrm{~kg}$ ) and $\mathrm{M}_{3}$ (maximum mass $>5000 \mathrm{~kg}$ ) refer to vehicles comprising more than eight seats in addition to the driver's seat.

One research area within the field of STS, recently given much attention, is safety. Many travelers are elderly and/or frail, traveling seated in wheelchairs and not in regular vehicle seats, and a majority of the travelers have few or no alternate modes of transport [2]. It has also been shown that STS travelers run the risk of being injured without being involved in a vehicle crash [4-7]. However, significant methodological challenges are connected to this type of investigation, since the official Swedish road traffic statistics only include vehicle-related injury events from police reported collisions [8]. Hence, other sources, such as hospital-based data, should be used in order to provide a broad and accurate picture of STS safety.

Previous research has underscored the significant difference in the coverage between hospital injury data and police injury data. Albertsson [9] concluded that a considerable underreporting existed (police injury data), even more often in the case of minor injuries. This finding was further supported by the fact that only $35 \%$ of all injuries reported in Swedish hospital data could be found 
Table 1

The 2008 Swedish Road Authority (SRA) version of valuation of safety in 2006 Swedish prices presented as USD (1 SEK=0.15 USD). International comparisons: the willingnessto-pay value for a serious injury is commonly assumed to be $10 \%$ of that for a fatality. For slight injuries, often only material costs are considered [20].

\begin{tabular}{|c|c|c|c|c|c|c|}
\hline Event & Material costs & $\begin{array}{l}\text { Health care costs part } \\
\text { of material costs }(\%)\end{array}$ & $\begin{array}{l}\text { Material costs of } \\
\text { total costs }(\%)\end{array}$ & $\begin{array}{l}\text { Value of risk reduction } \\
\text { per se }\end{array}$ & $\begin{array}{l}\text { Risk values of } \\
\text { total costs (\%) }\end{array}$ & $\begin{array}{l}\text { Total average cost per } \\
\text { casualty }\end{array}$ \\
\hline Fatality & 198,150 & 3 & 6 & $3,150,000$ & 94 & $3,348,150$ \\
\hline Severe injury & 99,150 & 50 & 16 & 522,900 & 84 & 622,050 \\
\hline Slight injury & 9,900 & 20 & 33 & 19,950 & 67 & 29,850 \\
\hline Property damage & 2,100 & 0 & 100 & 0 & 0 & 2,100 \\
\hline
\end{tabular}

in Swedish police data [10]. Björnstig et al. [8] report the same phenomenon, and so do Bylund et al. [11], in particular with respect to the degree of severity. Hence, a mixed method approach using multiple sources should be chosen when investigating STS related injuries.

Many injuries are related to non-crash events, such as abrupt braking and boarding/alighting [7]. This, in turn, further suggests that a different approach than the traditional crash investigation has to be adopted, namely a traveler/incident perspective, previously used in the studies of bus and coach injuries [8,12,13]. An incident is defined as an injury event resulting in a personal injury, measured in terms of maximum AIS (MAIS), according to the Abbreviated Injury Scale (AIS) [14]. Moreover, in order to study STS, the so-called "Travel Chain Perspective" [15] must be applied, i.e. a STS trip should be viewed from a wider perspective, meaning that the entire trip from door-to-door is taken into account.

Society would benefit indirectly from enhanced safety. Personal injuries related to STS impose large sums in material costs, i.e. health care costs, net production loss and property damage [16]. However, the safety measures would also impose additional costs directly on the transport providers, who would probably not be pleased.

The Swedish Road Administration (SRA) has adopted the willingness-to-pay (WTP) concept $[16,17]$ when estimating society's marginal benefit for every casualty avoided. This valuation consists of several dimensions. It contains both material costs including health care costs, value of net lost production and cost of property damage and administration - and an evaluation of risk reduction per se - covering the value of consumption lost due to premature death. As shown in Table 1, material costs represent only a minor part of the total valuation of safety as decided by SRA.

Within this concept, a severe injury is not set against the AIS scale [14], but as a percentage figure against a fatal injury, i.e. a severe injury representing $19 \%$ and a slight injury $1 \%$ of a fatality. In adopting this concept, Persson [16] advocates focusing on incidence rather than prevalence of injuries, due to the fact that the costs connected to the injury, on average, need to be viewed over a period of 2-8 years.

Estimations of the societal costs for traveler injuries related to STS could readily be made. Yet they need to be based on STS injury incidence, injury severity, and type of vehicle. Such estimations will even further contribute to our overall understanding by being specified according to the type of vehicle and traveler characteristics, in order to identify possible interventions to be taken and measures to be implemented. At present, these parameters remain unknown for Swedish conditions. However, Bylund et al. [13] have made an initial attempt including all STS passengers (ambulant as well as wheelchair-seated passengers).

\subsection{Aim and scope}

The aim of the study was to utilize a traveler/incident perspective to estimate the incidence and societal costs for wheelchair-seated passenger injuries related to STS. The current study limited the scope to demand-responsive road transport and the use of $M_{1}, M_{2}$ and $M_{3}$ vehicles within STS. For further descriptions of the approach, see also Bylund et al. [13].

\section{Materials and methods}

In this study, four different types of materials from different sources were used. The sources were chosen in order to obtain a wide perspective on travelers' injuries sustained during STS trips. These trips encompassed the entire travel chain from door-to-door. As a comparison, the wheelchair samples in this study were subsamples of all users of STS. In Material 1 the total number of injured STS users was 32 (28\% wheelchair users), in Material 2, 77 (34\% wheelchair users), and in Material 3, 50 (88\% wheelchair users).

\subsection{Material 1; hospital data}

Material 1 was obtained from an urbanized county and comprised 9 travelers using wheelchair during a STS trip in STS taxi or STS special vehicles (minibuses/minivans-usually taking either 8 ambulant passengers or 4 plus 2 wheelchairs). The persons were treated for injuries at a University Hospital after an incident during the transport. The population studied was all the people registered in the STS traveler register files at the municipal STS department. The data file from the municipality was matched by social security number to the regional Injury Surveillance Register (ISR) at the hospital. The ISR is based on a questionnaire answered on arrival at the emergency department (ED) by the patient or with assistance from personnel at the ED. Data from medical records and available police records are also included in the database. The calculation of injury incidence was based on data for the years 1998-2004 because numbers of STS trips $(1,134,500)$ were only available for those particular years. The average trip distance was about $6.1 \mathrm{~km}$. Henceforth, Material 1 denotes the hospital-based material.

\subsection{Material 2; municipal data}

Material 2 was obtained from a highly urbanized county, and comprised 26 persons using wheelchairs and injured during STS travel, as reported by the traveler, the driver or another person to the STS City Department. Data were extracted from the incident reporting system (the authority's deviation reporting system, comprising unique incidents: specific trips and persons) during the 2-year period February 1st 2003-January 31st 2005 comprising $2,680,500$ trips. The exact average distance was unknown. However, in further calculations, the distance $10 \mathrm{~km}$ (estimated by the authority) was assigned to this material. Henceforth, Material 2 denotes STS material together with Material 3.

\subsection{Material 3; county data}

Material 3 was obtained from a highly urbanized county, and comprised 44 injured persons using a wheelchair during STS in special transport vehicles only, as reported by the traveler, the driver or another person to the STS County Council Department. Data were extracted from the incident reporting system (unique incidents: specific trips and persons) during the 2 -year period February 1st 
Table 2

Population data, interview sample, Material 4. Number of trips equals number of interviews.

\begin{tabular}{|c|c|c|c|c|c|c|}
\hline \multirow[t]{2}{*}{ Area } & \multicolumn{3}{|l|}{ Population } & \multicolumn{3}{|l|}{ Sample } \\
\hline & Eligible for STS & $\begin{array}{l}\text { Eligible for STS, per } \\
1000 \text { inhabitants }\end{array}$ & $\begin{array}{l}\text { Average number of } \\
\text { trips per traveler }\end{array}$ & $\begin{array}{l}\text { Number of interviews } \\
\text { per area, daily }\end{array}$ & $\begin{array}{l}\text { Number of interviews } \\
\text { per area, totally }\end{array}$ & Wheelchair users \\
\hline (I) Västernorrland county & 11,857 & 49 & 20 & 7 & 456 & 70 \\
\hline (II) Stockholm county & 79,041 & 42 & 39 & 5 & 292 & 40 \\
\hline (III) Karlstad municipality & 3,668 & 45 & 27 & 2 & 124 & 21 \\
\hline (IV) Linköping municipality & 5,623 & 41 & 59 & 2 & 128 & 15 \\
\hline Total & $372,864^{*}$ & $41^{*}$ & $33^{*}$ & 16 & 1,000 & 146 \\
\hline
\end{tabular}

Denotes the total in Sweden, 2004.

2003-January 31st 2005, comprising 1,386,500 trips. The average distance was about $12.2 \mathrm{~km}$. Henceforth, Material 3 denotes STS material together with Material 2.

\subsection{Material 4: telephone interviews}

Material 4 was obtained through the Swedish Public Transport Association, which is the trade organization of local and regional public transport in Sweden. The organization continuously measures customer satisfaction among STS travelers throughout Sweden. The purpose is to measure the functional quality of demand-responsive transportation, quality assurance and benchmarking among the STS providers. The present study used an ongoing telephone survey, by adding specific questions regarding safety issues.

Based on all registered nationwide STS trips made the day before, the telephone survey makes up a random trip sample. Previously selected travelers received a "quarantine mark" in order to prevent annoying, repetitive telephone survey calls. The trip samples were available for analyses two days after the actual trips were made. The general questions in the standard survey addressed some background data, booking and trip quality issues. Additional background data were already at hand through STS eligibility data. The interviews were made in four different geographical areas: semirural county (I), highly urbanized county (II), and two mid-sized municipalities (III-IV), as shown in Table 2.

After approval (informed consent), two main issues were addressed. All subjects were asked whether a non-injury incident or an incident occurred during the trip in question. They were also asked about previous experiences of non-injury incidents or incidents. If this was the case, further clarifying questions followed. The answers were classified into the following parts of the so-called travel chain: to and from the vehicle side, during boarding/alighting the vehicle, or simply during the ride. Furthermore, questions about time, type of injury sustained (body part and severity), medical treatment needed, various health consequences etc., were asked. Henceforth, Material 4 denotes telephone interview material. This material was the only one addressing event that "potentially" could cause injuries.

\subsection{Injury severity}

Injuries were classified according to the Abbreviated Injury Scale [14]. MAIS stands for maximum AIS, i.e. the most severe injury. AIS $=1$ designates minor injuries, AIS $=2$ moderate injuries (e.g. concussion), AIS $=3$ serious injuries (e.g. femur fracture or spleen rupture) and AIS =4-6 designate severe, critical and maximum injuries.

\subsection{Methodological and ethical considerations}

The hospital material included only STS travelers treated for an injury at the emergency department. This implies that those sustaining minor injuries could have been treated elsewhere by a family practitioner or by the medical staff at senior residences. Information from the STS registration of injury events and incidents was likely to be incomplete, as dropouts may occur [7]. The interview material relies solely on self-reported events, with all the inherent implications connected to such a procedure.

Materials 1-3 are from totally different regions, so there can be no overlap. Material 4 might have covered Materials 2 and 3 . However, the calculations are made separately, and no cases have been added across materials.

The injury severity grade (MAIS) for the hospital-based material has been performed by studying the medical records for all cases. Regarding those cases based only on STS registers, most MAIS values have been derived from the self-reported injury description, as was the case with the interview material.

The study was approved by the Ethical Committee of the Medical Faculty at Umeå University (Dnr 04-129M). The interview material was delivered from the telephone interview company, already coded into an SPSS ${ }^{\circledR}$ data file in order to maintain traveler anonymity. Frequencies were calculated, cross tables were analyzed, text strings were manually coded, variables were recoded etc. Non-parametric methods (based on $\chi^{2}$-distribution) were used.

\section{Results}

The results will present the hospital-based material and the STS material combined in Sections 3.1-3.3. Data from the interview material are presented separately in Sections 3.4-3.6, since they are self-reported. Age distribution is presented in Fig. 1.

\subsection{Injury mechanism, Materials 1-3}

\subsubsection{Vehicle at standstill}

Of the 79 cases, more than half $(41 ; 52 \%)$ were injured when the vehicle was at a standstill. Most of the incidents (24) happened during transport to and from the vehicle sitting in a wheelchair.

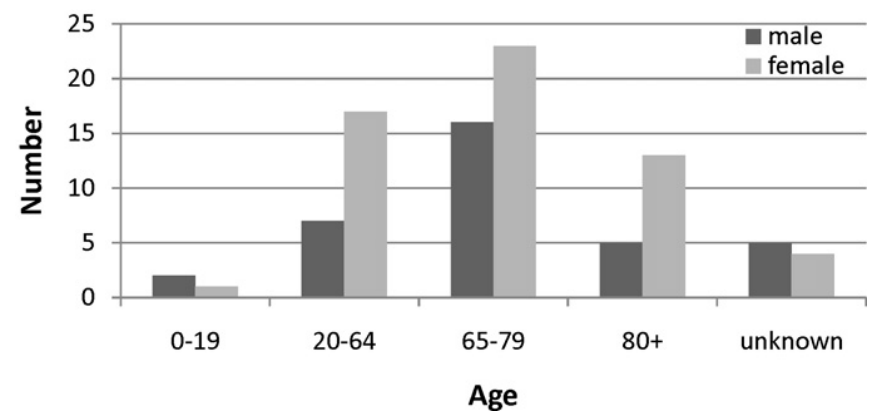

Fig. 1. The age and sex distribution of people injured during or in connection to STS transportation in a wheelchair (hospital data, municipal data, county data, telephone interviews (1-4); $n=93$ ). 
Nine of those 24 persons were injured when the driver was using stair climbing devices (managing the stairs at home or at the destination), either hitting against an object (5) or falling from the wheelchair (4). Six travelers were injured when the wheelchair overturned on a level surface, often caused by incorrect use of antitippers. Another six people sitting in wheelchairs were injured in other incidents. Finally, three were injured when they slipped from the wheelchair onto the ground.

Seventeen incidents occurred while boarding/alighting the vehicle. Of them, nine people fell when the wheelchair overturned and seven of the nine overturning incidents occurred on the ramp of STS special vehicles. Four people sitting in wheelchairs were injured when a foot/leg hit an object (3) or the person slipped out of the wheelchair (1). Another four incidents (falls or hitting against objects) happened when the driver helped the traveler to transfer from the vehicle seat to the wheelchair.

\subsubsection{Moving vehicle}

A vast majority $(34 ; 89 \%)$ of the incidents while the vehicle was moving happened in non-crash incidents, often (26) in connection with braking, accelerating, turning or driving over speed bumps, causing wheelchairs to overturn or passengers to slide out of their wheelchairs. In addition, three were injured in incidents with overturning wheelchairs but no information was available regarding the cause of the incident. Three passengers were injured after being hit by poorly fastened equipment (stair climbing devices, rollators, child seats) in the vehicle. Two people sustained injuries in other incidents. In 29 of the 34 cases the traveler was not properly restrained or secured, even though each vehicle should be equipped according to regulations and the driver is responsible for carrying out the wheelchair safety procedures.

Four people were injured in collisions, two in collisions with other vehicles, one when the vehicle was reversing and hit a pole, and another incident occurred when a man sitting in his motorized wheelchair and waiting for transport was hit by a reversing STS special vehicle.

\subsection{Injury severity related to the vehicle being at a standstill or moving, Materials 1-3}

Ten of the injured (13\%) sustained moderate or more serious injuries (MAIS 2+). Six of the MAIS 2+ cases occurred in noncollisions when the vehicle was moving, often in connection with abrupt braking. The other four MAIS2+ cases happened during transport in the wheelchair $(n=2)$, transferring from a regular seat to a wheelchair or when a motorized wheelchair overturned during a maneuver on the STS special vehicle ramp.

\subsection{Injury type and localization, Materials $1-3$}

The most common injuries among the 79 persons were bruises/abrasions (72\%), mostly affecting the lower extremities and the head. Ten people sustained fractures (lower extremities: $n=7$, thorax: $n=2$, head: $n=1$ ) and one person had a concussion.

\subsection{Background data, Material 4}

Of the 1000 respondents in the interview material, barely $15 \%$ (146) were wheelchair users, indicating a vast majority of ambulant travelers in STS. The trips by wheelchair users were commonly categorized as leisure trips (40\%), health care trips (23\%), shopping/service (23\%), work/study related trips (10\%) and others (4\%). Sixteen percent of the wheelchair users traveled daily, $57 \%$ once or a couple of times weekly, $19 \%$ once or a couple of times monthly, whereas $8 \%$ traveled "more seldom". The wheelchair users (mean age 67, SD 19) traveled more frequently than the ambulant passengers, whose mean age also was higher $(78$, SD 13$)$. The data were primarily divided into subsets from the "actual trip" (the trip which the respondents had made the day before the interview) and from "general experiences" (responses referring to any other trip made earlier).

\subsection{Incidents and injuries, Material 4}

Six respondents stated that a non-injury incident or an incident had occurred the day before $(N=146)$. Three of the incidents occurred "during the ride", and the other three occurred during transport to and from the vehicle or during boarding/alighting. However, among these six incidents, only one sustained minor injuries (contusions). As was expected, a low injury frequency was found. Therefore the following results will focus on the "general experiences", using stated travel habits for calculation of injury incidence.

The results showed that $21 \%$ had experienced a non-injury incident or an incident while using STS (excepting those 6 persons the day before; $\left.N=140, n_{\text {yes }}=30, n_{\text {no }}=110\right)$. Thirty of all these events happened during the year of the interview (2005), 33 up to two years ago and the rest earlier. Almost 7\% of the respondents had been injured while using STS. There was also a tendency that those who traveled more often also to a greater extent reported experiences of a non-injury incident or an incident $\left(\chi^{2}, p<0.01\right)$.

Scrutinizing the data further revealed that no geographical area was more prone to injuries than any other. Neither gender, nor age, nor type of wheelchair or impairment could predict injury experience. Furthermore, none of the background variables provided any indication of significant differences regarding duration of medical treatment processes.

\subsection{Injury mechanism and type, Material 4}

The most common events, classified as a non-injury incident or an incident, occurred while riding (69\%), during boarding and alighting (19\%), or transport to and from the vehicle. However, if only personal injuries were considered, $50 \%$ occurred during boarding or alighting and 50\% when "vehicle was moving". Thus, although the most commonly recalled event seemed to have happened during the ride, injuries tended to occur equally often during boarding or alighting. In other words, it seems that "a vehicle in motion" only accounts for half of the injury-related events among wheelchair users in STS transit.

Of the 10 injured respondents, a total number of 14 specified injuries were reported. The "vehicle at standstill" was associated with 5 MAIS 1 and 2 MAIS 2+ injuries. Similarly, the "moving vehicle" was associated with 2 MAIS 1 and 5 MAIS 2+ injuries. Based on these small absolute numbers, it still seems as "moving vehicle" could cause more severe injuries. However, none of these incidents were collisions; they only involved turns, abrupt braking or accelerating. The incidence rate was calculated based on the travel data (Materials 1-3) and respondents' stated travel habits (Material 4) (see Table 3).

\subsection{Estimation of incidence and costs}

A calculation based on 1.7 million annual STS trips with an incidence rate of 10 per 100,000 trips (see Table 3 ) will result in approximately 170 injured occupants to be expected in Sweden per annum. Most of them, about $82 \%$, will be "slightly injured", as described in terms used by Persson [16], while only a small percentage (18\%) will sustain a MAIS 2+ injury, which equals the term "severe injury" used in Table 1 . Furthermore, the maximal societal costs could then be estimated 
Table 3

Injury severity related to the vehicle being at standstill or moving and injury incidence per 100,000 trips (hospital-based material+STS material; $n=79$, and interview material; $n=14$ ).

\begin{tabular}{clll}
\hline Type of injury event & $\begin{array}{l}\text { Hospital material +STS } \\
\text { material (1-3) }\end{array}$ & $\begin{array}{l}\text { Interview } \\
\text { material (4) }\end{array}$ & Total (1-4) \\
\hline Vehicle at standstill & $n=41$ & $n=7$ & $N=48$ \\
MAIS 1 & $n=39(90 \%)$ & $n=5(71 \%)$ & $N=44$ \\
MAIS 2+ & $n=4(10 \%)$ & $n=2(29 \%)$ & $N=6$ \\
Vehicle moving & $n=38$ & $n=7$ & $N=45$ \\
MAIS 1 & $n=32(84 \%)$ & $n=2(29 \%)$ & $N=34$ \\
MAIS 2+ & $n=6(16 \%)$ & $n=5(71 \%)$ & $N=11$ \\
All injury events & $n=79$ & $n=14$ & $N=93$ \\
MAIS 1 & $n=69(87 \%)$ & $n=7(50 \%)$ & $N=76(82 \%)$ \\
MAIS 2+ & $n=10(13 \%)$ & $n=7(50 \%)$ & $N=17(18 \%)$ \\
STS taxis & $n=2$ & $n=0$ & $N=2$ \\
STS special vehicles & $n=77$ & $n=14$ & $N=91$ \\
Incidence & 10.1 & $9.7^{\mathrm{b}}$ & 10 \\
\hline
\end{tabular}

a Per 100,000 trips (single trip).

b Ranging from 4.8 to 12.6 , depending on self-reported traveling uncertainty. Time span assessed according to Wretstrand et al. [7].

to be about 23 million USD per annum, or 14 USD per trip $(170 \times(0.18 \times 622,050+0.82 \times 29,850))$.

\section{Discussion}

The aim of the present study was to estimate the incidence rate and societal costs for traveler injuries related to STS, utilizing a mixed method approach. This methodology proved to be useful, despite "small numbers". However, taking into account the fact that all four materials in the study pointed towards more or less consistent incidence figures, ranging from 9.7 to 10.1 injuries per 100,000 trips, it could be argued that the results are fairly reliable. The study by Bylund et al. [13] estimated incidence rates ranging from 1.5 to 5.6 injuries per 100,000 trips for both ambulant and wheelchair-seated STS passengers. This comparison underscores the fact that wheelchair users are a particularly vulnerable group of STS passengers.

The drawback of this study was that Materials 1-3 were selected with aim of getting valid and informative data. However, the selection focus on urban areas implies a risk of selection bias in the sense that areas included could be assumed to have a better standard of safety than areas not included. The fact that the agencies chosen have developed procedures for collecting incident data might suggest that these agencies also have prioritized safety issues. However, since the incidence figures do not drastically differ among the four materials, we have drawn the conclusion that they nevertheless all reflect a reasonably true state. Another weakness of Material 1 is that not all injuries may have been treated at the hospital, but at smaller units that were not covered by the database. Alternatively, some injuries sustained during the period may not have been treated at all, as suggested by Wretstrand et al. [7].

The sampling procedure in the interview material could be questioned, since it was not possible to draw a weighted stratified sample. The actual sample had to be adapted to the areas available for surveying. Furthermore, previous experiences [2] have pointed to difficulties when interviewing STS travelers. Many are old and frail, both mentally and physically. It may be difficult to understand or even see the point of the content and scope of the questions posed. Events that have occurred in the past can be difficult to recollect. Nevertheless, the incidence figure has provided a rough estimation, striving for validity and reliability through different methodological lenses.

Furthermore, it could be estimated that the maximal societal costs are about 23 million USD per annum. For this sum, substantial improvements of the boarding and alighting conditions could be made, as well as improvements of the passive safety inside the
Table 4

Killed and severely injured (KSI) rate per 100 million 1994-1998, [10].

\begin{tabular}{lcc}
\hline KSI rate per 100 million & & \\
\hline Mode of travel & Passenger kilometer & Passenger trips \\
\hline Car & 1.2 & 51.5 \\
Motorcycle/moped & 7.4 & 44.7 \\
Cycle & 11.9 & 69.6 \\
Foot & 8.3 & 20.9 \\
Bus or coach & 0.1 & 7.6 \\
Rail & 0.0 & 0.2 \\
Air travel $^{\mathrm{a}}$ & 0.1 & 147.3 \\
\hline
\end{tabular}

a Only for 1994-1997, no 1998 data available.

vehicles, as proposed by LeClaire et al. [18]. However, in order to promote and implement these measures, transport companies alone cannot easily be persuaded to invest in safety, since the incidence figures from a layman's perspective seem quite low. Rather, the transit authorities, which subsidize STS by around $90 \%$, need to focus more sharply on societal issues and costs, acknowledging the cross-sectional benefits.

The overall average incidence seems to be extremely high, compared to data in Table 4 (note that these are per million trips) [10]. However, some major perplexities are involved in this comparison. First, the occupant characteristics are probably quite different. Second, the measurement injuries per trip will have extremely different denominators, which might suggest passenger mileage as a more sensible denominator. Third, in the comparison data the term "killed and seriously injured" (KSI) was used. This indicated that the injured occupants in that database were more seriously injured than the sample in the four materials used in the current study. KSI excludes slight and moderate injuries, i.e. injuries more likely to be classified as MAIS 1 and 2. However, from the material in our study the division has been between MAIS 1 and 2+. As shown in Table 3, only $18 \%$ of the injuries sustained were MAIS $2+$, and only a very few of them MAIS 3+. Taken together, our incidence rate comparisons should be regarded with great care. Nevertheless, they form the basis for an "educated guess" of the societal costs for STS related injuries sustained by wheelchair-seated passengers.

A lot of energy and research have targeted wheelchair user safety, which has clearly benefited this passenger group. However, following the present study, the situation "vehicle at standstill" seems almost equally important. Traditionally, wheelchair transport safety research has focused on WTORS, the general belief being that if they are properly used, an injury is not likely to occur. Therefore it is essential to incorporate studies on wheelchair propulsion stability, design of safe boarding devices and driver training, in order to improve overall transport safety throughout the whole travel chain from door-to-door.

This study has had its focus on the passenger. Implicitly, STS also requires a highly supportive, engaged and trained driver. Thus, it appears more or less salient that what has been described as a passenger safety problem is, in fact, also a workplace problem for the drivers. As they are involved in boarding and alighting on a daily basis and, furthermore, exposed to poorly fitted safety equipment and loose technical aids and other luggage inside the vehicle in case of a crash [19], the workplace safety for the driver may be questioned. This is yet another approach to enhancing road transportation safety for STS users waiting to be explored.

\section{Conclusion}

The present study concludes that the injury incidence rate in STS is considerable (i.e. 10 per 100,000 trips). However, this is not due to road traffic collisions, but to non-collision injury incidents involv- 
ing many elderly and frail passengers who easily sustain injuries from minor to moderate traumas. Even though the proportion of moderate and severe injuries was slightly higher when the vehicles were moving, the study has pointed out that future injury mitigation must also focus on preventive safety for boarding and alighting procedures.

\section{Acknowledgements}

This study was founded by the Swedish Road Administration (Grant no. AL90 B 2003:26842). The authors would like to thank Emma Qvarfordt, Leif Bärlin, and Fredrik Forsell for their assistance in data collection.

\section{Conflict of interest}

None.

\section{References}

[1] SIKA. Special transport services and national special transport services 2004. Stockholm: The Swedish Institute for Transport and Communications Analysis; 2005.

[2] Wretstrand A, Stahl A, Petzall J. The safety of passengers in wheelchairs in special transportation services studied with interviews and assessments. Technology and Disability 2003;15(4):259-69.

[3] Directive 2001/85/EC of the European parliament and of the council of 20 November 2001 relating to special provisions for vehicles used for the carriage of passengers comprising more than eight seats in addition to the driver's seat, and amending Directives 70/156/EEC and 97/27/EC. Official Journal of the European Communities 2002;L 42(13/02/2002(2001/85/EC)):1-102.

[4] Falkmer T, Gregersen N-P. Perceived risk among parents concerning the travel situation for children with disabilities. Accident Analysis and Prevention 2002;34(4):553-62.
[5] Shaw G. Wheelchair rider risk in motor vehicles: a technical note. Journal of Rehabilitation Research and Development 2000;37(1):89-100.

[6] van Roosmalen L, Bertocci GE, Hobson DA, Karg P. Preliminary evaluation of occupant restraint system usage in motor vehicles. Journal of Rehabilitation Research and Development 2002;39:83-93.

[7] Wretstrand A, Petzäll J, Ståhl A. Safety as perceived by wheelchair-seated passengers in special transportation services. Accident Analysis and Prevention 2004;36(1):3-11.

[8] Björnstig U, Albertsson P, Björnstig J, Bylund P-O, Falkmer T, Petzäll J. Injury events among bus and coach occupants-non-crash injuries as important as crash injuries. IATSS Research 2005;29:79-87.

[9] Albertsson P. Occupant casualties in bus and coach traffic-injury and crash mechanisms. Dissertation. Umeå: Umeå University; 2005.

[10] ECBOS. Task 1.1. Report. Graz: Technical University Graz; 2001.

[11] Bylund P-O, Björnstig U, Björnstig J. Drop-out analysis-hospital based registration at the University hospital in Umeå. OAG 95. Umeå: AKMC; 1999.

[12] Albertsson P, Björnstig U, Falkmer T. The Haddon matrix, a tool for investigating severe bus and coach collisions. International Journal of Disaster Medicine 2004:1(2):109-19.

[13] Bylund P-O, Wretstrand A, Falkmer T, Lövgren A, Petzäll J. Injuries in STS travel-a multi-methodology approach to estimate incidence and societal costs. Traffic Injury Prevention 2007;8:180-8

[14] AAAM. The Abbreviated Injury Scale 1990 revision. Des Plaines, IL: Association for the Advancement of Automotive Medicine; 1990

[15] Carlsson G. Travelling by urban public transport: exploration of usability problems in a travel chain perspective. Scandinavian Journal of Occupational Therapy $2004 ; 11(2): 78-89$.

[16] Persson U. Valuing reductions in the risk of traffic accidents based on empirical studies in Sweden. Dissertation. Lund: Department of Technology and Society, Lund University; 2004.

[17] Jones-Lee MW. The economics of safety and physical risk. Oxford: Basil Blackwell; 1989.

[18] LeClaire M, Visvikis C, Oakley C, Savill T, Edwards M, Cakebread R. The safety of wheelchair occupants in road passenger vehicles. London: Mobility and Inclusion Unit, Department for Transport; 2003.

[19] Falkmer T, Gregersen NP. A questionnaire-based survey on the road vehicle travel habits of children with disabilities. IATSS Research 2001;25(1): 32-41.

[20] ETSC. Transport accident costs and the value of safety. European Transport Safety Council ETSC; 1997. 